\title{
Searching for the Parallel Growth of Cities
}

\author{
Zhihong Chen \\ School of International Trade and Economics \\ University of International Business and Economics \\ Beijing 100029, China \\ Email: zhihong.chen@uibe.edu.cn \\ Shihe $\mathrm{Fu}^{*}$ \\ Wang Yanan Institute for Studies in Economics \\ Xiamen University \\ Xiamen, 361005, China \\ Email: $\underline{\text { fushihe@xmu.edu.cn }}$ \\ Dayong Zhang \\ Research Institute of Economics and Management \\ Southwestern University of Finance and Economics \\ Chengdu, 610074, China \\ Email: dzhang@swufe.edu.cn
}

April 9, 2011

\begin{abstract}
Based on the parallel growth implications of the four urban growth theories (endogenous growth theory, random growth theory, hybrid growth theory, and locational fundamentals theory), this paper uses the Chinese city size data from 1984-2006 and time series econometric techniques to test for parallel growth. The results from various types of stationarity tests show that city growth is generally random. Conditioning on growth trend and structural change, certain groups of cities with common location specific characteristics, such as similar natural resource endowment or policy regime, grow parallel in the long run, suggesting that locational fundamentals may have persistent impacts on city growth.
\end{abstract}

Keywords: Urban growth; Parallel growth; Zipf's law; Locational fundamentals

JEL Classification: C22; R11; R12

\footnotetext{
* Corresponding author. The authors would like to thank Yves Zenou, two anonymous referees, Richard Arnott, Michel Dimou, Yuming Fu, Li Gan, Arthur Lewbel, Zhijie Xiao, the participants of the 2005 Chinese Economist Society annual conference, the 2006 AREUEA-Asian Real Estate Society international conference, 2007 European Regional Science Association conference, and the seminar at Southwestern University of Finance and Economics for very helpful comments. Zhihong Chen acknowledges financial support from the "Project 211(Phase III)" of the University of International Business and Economics (Grant 73200001); Dayong Zhang acknowledges financial support from the "Project 211(Phase III)" of the Southwestern University of Finance and Economics.
} 


\section{Introduction}

City growth across countries exhibits two striking facts. First, cities keep growing in many countries, in terms of both city size (city population) and the number of cities. Second, the distributions of city sizes in different countries fit the power law (Pareto distribution) very well. Especially, in the upper tail of city size distribution, the power exponent is equal to or very close to one, which is called Zipf's law or rank-size rule, meaning that a city size is proportional to the inverse of its rank. ${ }^{1}$

A recent simulation study by Gan, $\mathrm{Li}$, and Song (2006) demonstrates that the very good fit of Pareto distribution is just a statistical phenomenon. ${ }^{2}$ Therefore, the more interesting focus should be to study the dynamics of urban growth process and growth determinants. Unfortunately, empirically, we are still not clear whether city growth is random or deterministic. If it is deterministic, does the growth converge (small cities grow faster), diverge (large cities grow faster), or parallel (all cities grow at the same speed)? If it is random, does growth of cities move together in the long run (also termed parallel growth in the long run) or move purely independently? Identifying these empirical regularities of city growth patterns can shed light on city growth forecasting and urban public policy design related to regional inequality.

Of particular interest is to test the parallel growth hypothesis. Theoretically speaking,

\footnotetext{
${ }^{1}$ There is rich literature on city size distribution. Let $R$ and $P$ denote the rank and population size of a city, then, the power law or Pareto distribution implies that the number of cities whose population exceeds $P$ is proportional to $P^{-\beta}$. The econometric specification is $\ln R=\alpha-\beta \ln P+\varepsilon$. With $\beta=1$, it is called Zipf's law (Zipf, 1949) or rank-size rule. However, to be specific, rank-size rule is only a good approximation of Zipf's law (Gabaix, 1999). Many studies find that the upper tail of city size distribution obeys Zipf's law quite well. For a comprehensive survey on city size distribution, see Gabaix and Ioannides (2004).

${ }^{2} \mathrm{Gan}, \mathrm{Li}$, and Song (2006) show that the high $R^{2}$ of the regression of rank on size is just a statistical property. However, their estimated values of $\beta$ are sensitive to the parameters of the distribution of the size variable. They argue that Zipf's law is just a statistical phenomenon, but, to be precise, their conclusion means that the Pareto distribution is a statistical phenomenon.
} 
the four strands of urban growth theories that have been developed to explain the two stylized facts, namely, the endogenous growth theory (Black and Henderson, 1999; Eaton and Eckstein, 1997), the random growth theory (Gabaix, 1999), the hybrid growth theory (Rossi-Hansberg and Wright, 2007), and the locational fundamentals theory (Fujita and Mori, 1996; Krugman, 1996), all have implications related to parallel growth. Empirically, to the best of our knowledge, we find only one study (Sharma, 2003) that has detected directly parallel growth of city sizes in the long run in India. Whether parallel growth of cities exists in other countries remains a mystery.

The endogenous urban growth theory predicts deterministic, persistent, parallel growth of cities, meaning that in steady state cities of different sizes grow at the same constant speed. The Black-Henderson model (Black and Henderson, 1999) assumes localized information spillovers and human capital accumulation as the engines of urban growth. This model produces endogenous city sizes and number of cities over time. Sizes of different types of cities grow at the same rate which is proportional to the growth rate of human capital accumulation; the number of cities of each type also grows at the same rate which equals the difference between the rate of national population growth and the rate of city population growth. A similar, deterministic, endogenous growth model by Eaton and Eckstein (1997) also predicts that the growth of a system of cities is parallel, with relative city sizes depending upon the knowledge spillover effects that cities can provide.

The random urban growth theory assumes that city sizes grow stochastically, to be specific, follow Gibrat's law (the growth processes have the common expected city growth rate and a common standard deviation), or in the continuous case, follow a geometric Brownian motion. If at least for a certain range of size, the cities follow Gibrat's law, then, 
regardless of whatever drives city growth, automatically in the steady state, the distribution of city sizes in that range will follow Zipf's law (Cordoba, 2007; Gabaix, 1999). If this theory is correct, the future research should focus on finding if and on explaining why the actual city size growth follows Gibrat's law. In terms of time series econometrics, Gibrat's law implies that the city size growth process is a random walk or a unit root process. ${ }^{3}$ Therefore, the random growth theory rejects deterministic parallel growth but implies that if parallel growth exists, it would be in the form of co-movement of unit-root processes, or cointegration of city sizes, in the long run.

The hybrid urban growth model proposed by Rossi-Hansberg and Wright (2007) combines both the endogenous growth model and Gibrat's law and predicts both city growth facts. A random total factor productivity shock is introduced to the model so that the balanced growth of city sizes is also random. Under two sets of restrictive conditions (e.g., eliminating physical capital), the expected long-run growth rate and variance are independent of city size, which fits Gibrat’s law. Under certain range of parameter values, the hybrid model can also generate distributions which deviate from Zipf's law, as uncovered by some empirical literature. This theory predicts parallel growth in the long run (same expected growth rates in steady state) but random deviation in the short run due to external productivity shocks, which is a special case of cointegration with the cointegrating coefficient equal to one.

3 To see this, consider a city with population $N_{0}$ at starting time 0 . The growth rate of population at time $t$, $g_{t}$, is a random variable independently distributed with mean $E\left(g_{t}\right)=\mu$ and variance $\operatorname{Var}\left(g_{t}\right)=\delta^{2}$, then $N_{T}=N_{0} \prod_{t=1}^{T}\left(1+g_{t}\right)$. If $g_{t}$ is relatively small, then the following approximation holds:

$\ln N_{T}=\ln N_{\mathrm{o}}+\sum_{t=1}^{T} g_{t}=\ln N_{\mathrm{o}}+\mu T+\sum_{t=1}^{T} \varepsilon_{t}$,

where "In" denotes $\operatorname{logarithm}$ and $\varepsilon_{t}$ is a white noise process. The above equation implies that $\ln N_{T}$ is a random walk with a drift parameter $\mu$ and that a random growth shock has a permanent impact on city size. 
The locational fundamentals theory states that natural advantage (first nature advantage) determines the existence and growth of cities (Fujita and Mori, 1996; Krugman, 1996). Locational characteristics may be considered randomly distributed over space (a spatial random process). They are the initial conditions which play a crucial role in shaping the formation and evolution of the size of that location. Even the initial conditions become unimportant any more, their effects may still persist, which is called the path dependence effect or the lock-in effect of self-reinforcing agglomeration forces (Fujita and Mori, 1996). Such self-reinforcing agglomeration forces could be due to first nature advantages creating second nature advantages through cumulative processes (Krugman, 1993). Furthermore, strong location-specific advantages may even revert the strong, temporary shocks to city growth, which is contrary to the random growth theory. Although this theory makes no clear prediction about the pattern of city growth, an inference can be drawn that if two cities have similar locational fundamentals, their growth should be close to parallel. Table 1 below summarizes the implication of each urban growth theory for parallel growth. (Insert Table 1 here)

Only a few empirical studies have tested parallel growth of cities. Junius (1999) uses a cross-country data and finds that the population proportion of largest cities (urban primacy ratio) in a country has a bell shaped relationship with economic development, rejecting parallel growth of cities. Although top cities might not grow parallel, whether other groups of cities tend to grow parallel is unknown. Using a time-series data from Indian decennial population censuses from 1901-1991 and applying unit root and cointegration test, Sharma (2003) concludes that city growth may be parallel in the long 
run, but the short-run growth may deviate from the long-run rate of growth due to exogenous shocks; and temporary shocks may take less than a decade to dissipate. ${ }^{4}$ However, Sharma specifies a very strong assumption that the time trend of growth is zero or negligible in order to produce parallel growth. She also neglects one of the key features of city size evolution-structural change.

This paper adapts the cointegration method in Sharma (2003) by relaxing the time trend assumption and taking into account endogenous structural change of city sizes and tests parallel growth of cities in the long run. Specifically, we use the Chinese city size time series data from 1984 to 2006 to identify the dynamic patterns of city growth.

Rapid urbanization has taken place in China since the 1980s. The urbanization rate increases from $23.01 \%$ in 1984 to $43.90 \%$ by the end of 2006 , and the total number of cities increases from 295 in 1984 to 661 in $2006 .{ }^{5}$ The dramatic change of Chinese economic structure and policies may have had strong impacts on the evolution of city sizes and size distribution. Some cities benefit from the strong agglomeration economies from nearby super-large cities or city-belt; some other cities, however, still suffer from locational disadvantages. Cities in special economic zones have been blessed by favorable government economic policies and grow much faster, but cities in the west inland are left behind. These special features of Chinese city growth have attracted a few studies on size distribution (Anderson and Ge, 2005; Song and Zhang, 2002) but few on the dynamics of Chinese city growth.

\footnotetext{
${ }^{4}$ It is interesting to note that Sharma's empirical study actually tests the hybrid growth theory and it is done before Rossi-Hansberg and Wright's theoretical work. A careful reader can find that Sharma's paper provides empirical evidence for Rossi-Hansberg and Wright's conclusion that cities grow parallel in steady state yet the growth processes follow Gibrat's law.

${ }^{5}$ The average urbanization rates in 1950 and in 2005 for the world are $29.1 \%$ and $48.6 \%$, respectively; for less developed regions, $18 \%$ and $42.7 \%$, respectively; for less developed regions excluding China, $20.2 \%$ and 43.4\%, respectively (World Urbanization Prospects: The 2007 Revision Population Database, available at www.un.org).
} 
Our research focuses on identifying the growth pattern of Chinese cities. The results from various types of stationarity (unit roots) and cointegration tests show that in general city growth is not parallel; however, once trend stationarity with endogenous structural change is allowed, cities with certain common group characteristics, in terms of geographic region, natural resource endowment, and policy regime, grow parallel. If any location-specific factors are considered locational fundamentals, then our findings lend some support to the locational fundamentals growth theory in the sense that cities with similar locational fundamentals tend to grow parallel in the long run.

The rest of the paper is organized as follows: Section 2 discusses the methodology of testing for parallel growth; Section 3 describes the data set; Section 4 presents the results; and Section 5 concludes.

\section{Testing parallel growth of cities}

The endogenous urban growth theory predicts simple, deterministic, parallel growth in steady state. Empirically, testing for the deterministic, parallel growth is straightforward: simply test whether individual cities' growth rates are constant and remain the same in each period. But, obviously, since city growth is affected by many factors (Angel, Sheppard, and Civco, 2005) and stochastic shocks, such a strict version of parallel growth is rare if not impossible.

If city size is a random process, then, testing parallel growth can be indirect, meaning that a stable city size distribution over time implies parallel growth. Alternatively, the test can be direct by means of cointegration method, but non-stationarity of or unit root in the city size time series data needs to be confirmed first. This section focuses on the methodologies for the indirect test for the stability of city size distribution and the direct 
test for comovement of random growth.

\subsection{Indirect test for parallel growth}

Whether Zipf's law for all cities is a statistical property or not, the relative stability of city size distribution in a country at different time periods suggests that cities of different sizes may grow relatively parallel. But the issue of indirect test is that if some cities change their ranks, then, stable size distribution does not imply perfect parallel growth. In general, the rank order of top cities rarely changes, as evidenced by Polèse and Denis-Jacob (2010) who use city size data from 126 countries since 1900. Cities of medium and small sizes probably change rank order more often. Nevertheless, stability of size distribution can still provide suggestive evidence for or against parallel growth. Eaton and Eckstein (1997) use France and Japan city size data and estimate the Markov transition matrix of city size evolution. They conclude that a wide range of city size growth is persistent, with quite stable distribution which is close to the rank-size rule. This is consistent with parallel growth. However, they use only the top 40 urban areas. As many studies have pointed out, the threshold of city size matters in estimating the power exponent. Also, as pointed out by Sharma (2003), they do not provide statistical inference concerning the estimated transition probabilities. It is hard to know how large the diagonal transition probability should be to justify the persistent, parallel growth. ${ }^{6}$

The by-product of the indirect test is that it can also test indirectly whether city growth is random or not. The random growth theory states that if city growth processes follow Gibrat's law, then the steady state distribution will obey Zipf's law. Therefore, if the city size distribution is not consistent with Zipf's law, we would cast doubt on the random

\footnotetext{
${ }^{6}$ Black and Henderson (1997) use similar methodology and find that the relative size distribution of American cities is "astonishingly" stable over time.
} 
growth. We use the Chinese city size data and estimate the standard rank-size model for each year to trace the change of the power exponent and the stability of city size distribution:

$$
\ln R=\alpha-\beta \ln P+\varepsilon,
$$

where $R$ and $P$ are the rank and population size of a city, "In” denotes natural logarithm, and $\beta$ is Zipf's exponent. Model (1) is estimated using the ordinary least squares method (OLS) and the results are discussed in Section 4.1. ${ }^{7}$

\subsection{Testing stationarity of city sizes}

The sizes of a city at different time periods are most likely correlated due to reasons such as the durability of urban infrastructure, housing, and fixed costs of production. The intertemporal correlation of city sizes implies that a temporary random shock to city size may have persistent impact on the future city growth. The random growth theory indicates that city size time series is a random walk, implying that a temporary shock will have permanent effects on city growth. If a random shock is identified to have only temporary effects on city size, then the random growth theory can be rejected. Davis and Weinstein (2002) find that one of the most powerful shocks to city size evolution in the human history - the Allied bombing of Japanese cities during the World War II-has only temporary effects: Most cities return to their relative positions in the distribution of city sizes within about fifteen years from the devastating destruction. This strongly strikes at the random growth theory. Brakman, Garretsen, and Schramm (2004) and Bosker et al. (2008) apply the similar methodology and also find that city growth in Eastern Germany follows a random walk but city growth in Western Germany does not, suggesting that

\footnotetext{
${ }^{7}$ Using OLS to estimate equation (1) will underestimate $\beta$ and its standard error when the sample size is small. Other methods such as the Hill estimator, also underestimate the standard error or have other drawbacks (Gabaix and Ioannides, 2004). Therefore, we rely on the OLS method only in this study.
} 
different post-war economic systems may have played an important role in shaping urban growth dynamics.

Testing the persistence of a random shock to city size boils down to the test for the stationarity of city sizes or the test for unit roots. If city size is detected to be non-stationary, then the cointegration approach can be applied to investigate parallel growth between cities.

Let $\ln P_{i t}$ denote the logarithm of the population of city $i$ at time $t$, then, the simplest specification for stationarity test is to assume that city size is a first-order autoregressive $(A R(1))$ process:

$$
\ln P_{i t}=\phi_{i} \ln P_{i, t-1}+\varepsilon_{i t} \text {, }
$$

where $\phi_{i}$ is the first-order autocorrelation coefficient and $\varepsilon_{i t}$ is the random shock at time $t$. The augmented Dickey-Fuller (ADF) test for non-stationarity (Dickey and Fuller, 1979) of population levels takes the form

$$
\Delta \ln P_{i t}=\gamma_{i} \ln P_{i, t-1}+\varepsilon_{i t},
$$

where $\gamma_{i}=\phi_{i}-1$. The null hypothesis is non-stationarity: $\phi_{i}=1$ (or $\gamma_{i}=0$ ). If $\phi_{i}<1$, city population will converge to a constant in the steady state. Since the conclusion of unit root test is sensitive to the specification of the model, we specify the model in the very general form, including a drift $\alpha_{i}$ and a linear trend $\beta_{i} t$ controlling for the deterministic trend:

$$
\Delta \ln P_{i t}=\alpha_{i}+\beta_{i} t+\gamma_{i} \ln P_{i, t-1}+\sum_{j=1}^{k_{i}} \rho_{i j} \Delta \ln P_{i, t-j}+\varepsilon_{i t},
$$

where $k_{i}$ is the number of lagged difference terms for city $i$.We choose the optimal lags using Bayesian information criterion (BIC). 
To make sure that the stationarity tests are reliable and robust, we also apply the KPSS test (Kwiatkowski et al., 1992). The null hypothesis of KPSS test is that the underlying time series is trend stationary, which is complementary to the ADF test. The KPSS test selects the optimal lag length automatically with Newey-West methodology. If the results from both ADF test and KPSS test agree with each other, then we will be confident of the stationarity characteristics of city sizes.

Since China's economic reform and transition to a market economy may have had very different impacts on city size dynamics during different time periods, it is worth taking into account structural change or breaking trend in the trajectory of city sizes. A methodology testing both unit root and endogenous structural break point simultaneously is the Zivot-Andrews (ZA) test (Zivot and Andrews, 1992). The null hypothesis of the ZA test is that the underlying time series $\ln P_{i t}$ has a unit root with drift $\mu$ :

$$
\ln P_{i t}=\mu+\ln P_{i, t-1}+\varepsilon_{i t} .
$$

The alternative hypothesis is that $\ln P_{i t}$ is trend stationary with a one-time break in the trend occurring at an unknown point of time. For example, suppose that $\ln P_{i t}$ has one structural change in the level, then, the regression equation for testing unit root is

$$
\Delta \ln P_{i t}=\mu+\theta D U_{t}(\lambda)+\beta t+\gamma \ln P_{i, t-1}+\sum_{j=1}^{k} \rho_{j} \Delta \ln P_{i, t-j}+\varepsilon_{i t},
$$

where $\lambda=t / T$ is the location of the break point and is chosen to give the least favorable result for the null hypothesis (5) and $D U_{t}(\lambda)=1$ if $t>T \lambda .^{8}$ Again BIC is applied to select the optimal lag length in the ZA test.

\footnotetext{
${ }^{8}$ Similarly, if we assume that $\ln P_{i t}$ has one structural change in the growth rate, then, the regression
} 
The various unit root testing results are reported in Section 4.2.

\subsection{Testing parallel growth of cities}

Even city sizes evolve in a non-stationary way, they still could move together as city growth is affected by many common factors, such as national economic growth or other nation-wide or regional-wide macroeconomic factors. A special case is that cities grow parallel in the long run but deviate in the short run, which is the prediction of the hybrid urban growth theory. Parallel growth of cities also implies that their population levels may move together with the national urban population. Sharma (2003) uses the Indian decennial population census data from 1901-1991 and conducts unit roots and cointegration tests. She concludes that city growth in the long run may be parallel to the national urban growth, but in the short run growth may deviate from the expected long-run rate of growth due to exogenous shocks.

However, two issues remain in Sharma's study. First, she does not consider structural changes of city sizes. The period of rapid industrialization and urbanization in each country is also accompanied by dramatic changes in economic structure and policy regime, which may have had persistent effects on later urban growth and different impacts on different cities. Therefore, structural changes should also be taken into account.

Second, Sharma specifies a very strong assumption that the time trend of growth is zero or negligible to generate parallel growth. Specifically, she specifies the following model to test parallel growth:

$$
\ln P_{i t}=\alpha_{i}+\delta t+\beta_{i} \ln P_{j, t-1}+\varepsilon_{i t}
$$

equation for testing unit root is $\Delta \ln P_{i t}=\mu+\beta t+\theta D T_{t}(\lambda)+\gamma \ln P_{i, t-1}+\sum_{j=1}^{k} \rho_{j} \Delta \ln P_{i, t-j}+\varepsilon_{i t}$, where $D T_{t}(\lambda)=t-T \lambda$ if $t>T \lambda$. We generally consider only the structural change in the level. 
where $P_{i t}$ denotes the population of city $i$ at time $t$. She argues that $\beta_{i}=1$ implies parallel growth. This argument is true only if the time trend $\delta$ is zero or $\delta$ is very small and can be neglected. To see this, let's assume that $\ln P_{i t}$ is a general first-order autoregressive $(A R(1))$ process with a unit root, a drift, and a time trend:

$$
\ln P_{i t}=\alpha_{i}+\beta_{i} t+\ln P_{i, t-1}+\varepsilon_{i t} .
$$

The expected growth rate $E\left(g_{i t}\right)$ at time $t$ is

$$
E\left(g_{i t}\right)=E\left(\ln P_{i t}-\ln P_{i, t-1}\right)=\alpha_{i}+\beta_{i} t .
$$

By the same token, the expected growth rate of city $j$ at time $t$ is

$$
E\left(g_{j t}\right)=E\left(\ln P_{j t}-\ln P_{j, t-1}\right)=\alpha_{j}+\beta_{j} t .
$$

The random parallel growth requires that for any $t$,

$$
\alpha_{i}+\beta_{i} t=\alpha_{j}+\beta_{j} t
$$

Therefore, parallel growth implies the same time trend across all cities, regardless of the magnitude of time trend.

We propose using a city size ratio test that does not require the small time trend assumption and is even simpler than the cointegration method. To demonstrate our approach, let's explain the cointegration method first. The long-run equilibrium relationship between two city sizes with parallel growth is

$$
\ln P_{i t}=\alpha_{i}+\ln P_{j t}
$$

If both $\ln P_{i t}$ and $\ln P_{j t}$ are unit root processes, the regression model for cointegration test can be specified as

$$
\ln P_{i t}=\alpha_{i}+\gamma \ln P_{j t}+\varepsilon_{i t}
$$


where $P_{j t}$ is the population level of a chosen reference city. If $\ln P_{i t}$ and $\ln P_{j t}$ are cointegrated and $\gamma \neq 1$, then city $i$ grows at a rate different from the reference city $j$. If $\ln P_{i t}$ and $\ln P_{j t}$ are cointegrated and $\gamma=1$, then the two cities grow parallel at the same expected long-run rate. While various methods of cointegration test, such as Johansen-Juselius cointegration rank test (Johansen and Juselius, 1990), are applicable here, a more convenient way is to test whether the logarithm of the ratio of two city sizes is stationary or not. To see this, suppose two city sizes grow parallel, then equation (7) can be re-written as

$$
\ln \left(P_{i t} / P_{j t}\right)=\alpha+\varepsilon_{i t},
$$

meaning that parallel growth of two cities requires that the ratio of two city sizes be stationary around a constant. Furthermore, if city $i$ grows faster than city $j$ by a constant rate, the relationship will be featured by a linear time trend:

$$
\ln \left(P_{i t} / P_{j t}\right)=\ln P_{i t}-\ln P_{j t}=\alpha+\beta t+\varepsilon_{i t}
$$

We can apply the same unit root test techniques in Section 2.2 to test whether the transformed time series data $\ln \left(P_{i t} / P_{j t}\right)$ is (trend) stationary. Another advantage of using equation (9) to test parallel growth is that we can take into account structural change in either or both cities under testing.

It would be unnecessary to compare all city pairs whose sizes are non-stationary to detect parallel growth. After experimenting random pairing, we decide to focus on cities with the same location-specific characteristics, such as same region or same major natural resource endowment. Results from estimating equation (9) for some city pairs with same locational fundamentals are presented and discussed in Section 4.3. 


\section{Data}

Before introducing the data, let's first summarize our testing methodologies based on the four urban growth theories. We will test whether Chinese city sizes obey Zipf's law and whether the distribution is stable over time; if not, we will reject the random urban growth theory and parallel growth. We will also test whether Chinese city sizes follow Gibrat's law or unit root processes; if yes, we will proceed to test for parallel growth. For parallel growth test, we use a modified cointegration test strategy shown in equation (9).

Our various tests use the annual Chinese city size data from 1984 to 2006. The data are from each year's China Urban Statistic Yearbook. In this paper a city is defined as “city proper,” including both inner city area and suburban areas but excluding independent suburban counties. ${ }^{9}$ City population is defined as the number of non-agricultural population in urban area of a city (by the permanent residence) at year-end. Non-agricultural population are those who engaged in non-agricultural vocations and their dependents.

Small sample size, especially short time period, is a notorious problem to the standard time series analysis, especially for the stationarity test and cointegration analysis. ${ }^{10}$ An obvious remedy is to expand the time span of the data set. But we are aware that before 1984 China employed different definitions of urban population and annual data are not available for the majority of cities. To deal with the small sample size problem, we interpolate annual city size time series data and transform them into a higher frequency

\footnotetext{
9 Although some independent suburban counties, officially speaking, belong to the administrative scope of a city, they do not actually function like an urban area. Therefore, the China Urban Statistical Yearbook advises users to use "city proper" when studying urban related issues.

10 For example, severe size distortions are found in stationarity test when a time series has a large negative moving average (MA) root (Schwert, 1989) or a large AR root (DeJong et al., 1992).
} 
data, that is, quarterly data. ${ }^{11}$ Of the two commonly used interpolation methods-the quadratic method and the cubic spline method, we use the second as recommended by Baxter (1998).

Chinese cities usually are classified into five size categories according to their population: small, medium, large, extra large, and super large-sized cities with population less than 200,000, between 200,000 and 500,000, between 500,000 and 1,000,000, between 1000,000 and 2,000,000, and above 2,000,000 persons, respectively. By region, Chinese cities traditionally are assigned to one of the following three categories: Eastern, Middle, and Western region. A more disaggregated regional classification consists of seven sub-regions: Northeastern, Northwestern, Southwestern, Northern, Eastern, Southern, and Middle China.

During the transition to a market-oriented economy and opening to the world, Chinese government has favored a small number of cities to implement reform and open policies, including 5 cities in special economic zones and 16 open coastal cities (starting from 1980) which we term "policy cities". For reasons that will be clear soon, we are also interested in another type of cities_tourism cities. In 1998 the National Tourism Administration of China nominated the first list of "Best Tourism City” including 54 cities.

\section{Results}

\subsection{Time Variations of Zipf's Exponent}

The random growth theory states that if city growth processes follow Gibrat's law, then the steady state distribution will obey Zipf's law. Therefore, if the Chinese city size distribution is not consistent with Zipf's law, we would cast doubt on the random growth.

\footnotetext{
${ }^{11}$ Interpolation is commonly used in macroeconomics to transform low frequency data into high frequency data. For example, Bernanke, Gertler, and Watson (1997) interpolate quarterly GDP data into monthly series when studying the effects of monetary policy.
} 
Moreover, if the distribution is not stable over time, parallel growth can be rejected. (Insert Table 2 here)

Table 2 reports the results from estimating equation (1) using the ordinary least square method. The coefficient $\beta$ in the third column is estimated using the full sample. The power exponent has been increasing from less than one in 1984 to quite greater than one in 2006, implying that the overall city size distribution becomes close to and finally more even than what Zipf's law predicts. In 19 out of 23 years an $F$ test rejects the null hypothesis that $\beta$ is equal to 1 . Column 8 presents the Zipf's exponent for the balanced panel that includes 259 cities existing during 1984-2006. The pattern is very similar to the full sample, suggesting that the city sample of the balanced panel is representative.

Since many empirical studies confirm that the exponent is sensitive to the sample choice and is close to one for the upper tail of size distribution (Rosen and Resnick, 1980; Eeckhout, 2004), we also estimate the model by selecting only cities of size greater than a certain large threshold. The fifth and seventh columns report the results for cities of size greater than 200,000 and 500,000, respectively. The estimated power exponents now are significantly different from one, to be specific, significantly greater than one. The values of $\beta$ increases when we move the cutoff to the upper tail, suggesting that larger cities distribute more evenly than what Zipf's law predicts. One possible explanation is that the Chinese government has implemented the policies that increasingly restrict the size of large cities since the 1980s. In 1980 the central government starts the urban planning policy that controls the size of large cities, appropriately develops medium cities, and actively develops small cities; however, in 1990 the Urban Planning Law clearly states a 
policy that strictly controls the size of large cities and appropriately develops medium-sized and small cities. Another interpretation is that the current size distribution may not be in the steady state. In fact, the overall size distribution of Chinese cities has been evolving. According to the United Nations data source, in 2007 the urbanization rate in China is $42.2 \%$, while the urbanization rate of developed countries is above $70 \%{ }^{12}$ China is still in the period of rapid urbanization and the distribution of city sizes will keep evolving. Historically, the power exponent shows a U-shaped pattern in many countries (Parr, 1985). Cross-country studies also show that the Zipf's exponent is significantly different from one (Nitsch, 2005; Soo, 2005). In addition, using the Chinese city size data up to 1999, Anderson and Ge (2005) find that Chinese city sizes are better described by a log-normal distribution. Given all these pieces of mixed evidence, we tend not to make conclusion about the random growth and parallel growth by looking at only the evolution of the power exponent.

\subsection{Non-stationarity in City Sizes}

We select cities in the balanced panel from 1984 to 2006 but exclude cities at the county level to do the unit root tests. ${ }^{13}$ Overall, both the ADF and KPSS tests show that 153 out of 210 cities have unit roots, suggesting that the sizes of most cities are not stationary. As a demonstration, Table 3 reports the unit root test results for some selected cities: panel 1 presents the cases that the ADF test and KPSS test are not consistent, panel 2 the cases that are consistently stationary, and panel 3 the cases that are consistently

\footnotetext{
${ }^{12}$ In 2005 the average urbanization rate for more developed regions is $74 \%$. In 2007, the urbanization rate of the USA is $81.4 \%$; Canada, 80.3\%; Japan, 66.3\%; United Kingdom, 89.9\%; France; 77.1\% (Source: World Urbanization Prospects: the 2007 Revision Population Database, available at www.un.org).

${ }^{13}$ A city at the county level is in general the capital of a county and is in general a small city. The definition of urban population for cities at the county level changed in 2005.
} 
non-stationary. It is worth noting that in panels 2 and 3 when both ADF and KPSS tests agree with each other, the ZA test tends to be consistent too.

(Insert Table 3 here)

It is well known that the power of unit root test based on single equation is poor, especially when the time series is short. Panel unit root tests with a large $N$ can improve the power. The time length of our data set is not very long; but the number of cities is large enough. For robustness check, for the 153 cities detected with unit root, we also conduct the Im-Pesaran-Shin panel unit root test (Im, Pesaran, and Shin, 2003) and the Levin-Lin-Chu panel unit root test (Levin, Lin, and Chu, 2002). Both test results can not reject the null hypothesis that all cities in the panel have unit roots (the values of Im-Pesaran-Shin test statistic and the Levin-Lin-Chu test statistic are 16.3 and 17.0, respectively). ${ }^{14}$

We also conduct unit root tests for population growth rate of the same set of cities, using the first-order difference of logarithmic population level. The null hypothesis of unit root of growth rate is rejected for all cities. Therefore, we conclude that the sizes of most of the cities in our sample are stochastic processes integrated with order one (I(1) processes).

Two inferences can be drawn from unit root tests. First, there exists no steady state size for the majority of cities. This rejects the conditional convergence hypothesis. Second, since for the majority of cities, city size is a non-stationary process and the rate of growth

\footnotetext{
${ }^{14}$ We also do a panel unit root test for the balanced panel of 210 cities. The values of Im-Pesaran-Shin test statistic and the Levin-Lin-Chu test statistic are -5.28 and -10.07, respectively, rejecting the null hypothesis of a unit root. This is not surprising since the balanced panel includes 57 cities without a unit root. Henderson and Wang (2007) apply panel unit root test using cross-country city level data and also reject unit root.
} 
is a stationary process, we cannot reject the random urban growth theory as confidently as do Davis and Weinstein (2002).

\subsection{Results for parallel growth}

After confirming that most of the city size time series has a unit root, we continue to test the stationarity of equation (9). It would be unnecessary to compare by pair all cities that are non-stationary to detect the growth pattern. ${ }^{15}$ We first select city pairs randomly, then select city pairs of same size, or of same region, or with same major government intervention (such as special economic zones) to test for parallel growth. Our preliminary finding is that the majority of cities do not appear to grow parallel; however, cities with the same location-specific characteristics, such as same region, same major natural resource endowment, and same policy intervention, are more likely to grow parallel. Therefore, as a representative demonstration, we present the results for seven groups of cities with similar locational fundamentals: tourist cities, capital cities, coastal cities, cities in Yangtze River Delta region and Pearl River Delta region, and cities in Southwestern region and Northeastern region. Our classification is rather suggestive and intuitive as it is hard to delineate and quantify locational fundamentals. In the literature, factors that represent locational fundamentals include both natural characteristics of a city such as latitude, rainfall, and distance to coastal line, and produced characteristics such as education infrastructures.

15 Sharma(2003) compares the cointegration between each city and the national urban population. However, the stationarity of national urban population depends on the highest order of integrated processes of individual cities. In addition, urban endogenous growth and hybrid growth theories suggest the parallel growth between cities, not between a city and national population. These are the reasons that we do not compare individual city size with national urban population. 
Table 4 provides the ADF, KPSS, and ZA test results for testing parallel growth for the seven groups of cities. To save space, for each group, we present only three cities that grow parallel with the reference city of each group.

(Insert Table 4 here)

(1) Tourism cities. Obviously, tourism cities have location-specific fundamentals - natural tourist attractions such as beautiful lakes, rivers, beaches, and mountains. Using Guilin as the reference city, we conduct parallel growth test for the 54 cities in the first list of the best tourism cities nominated by the National Tourism Administration of China in 1998. Panel 1 of Table 4 reports the test statistics for three cities that grow parallel with Guilin. It is interesting to see that Hangzhou and Suzhou satisfy parallel growth condition with one level shift occurring at the same date (the second quarter in 2000). These two cities are geographic neighbors in Zhejiang province but Hangzhou is a capital city. Figure 1 plots the logarithm of population levels for Hangzhou, Suzhou, and Guilin. Visually we can see that the three cities grow parallel if we ignore the break point occurring in 2000 for Hangzhou and Suzhou. Figure 2 plots the logarithm of population ratio for Hangzhou and Suzhou compared with Guilin, and the patterns are remarkably similar. Taking together, we tentatively conclude that natural tourist attractions might play a very important role in long-run urban growth for tourism cities.

(Insert Fig.1 and Fig.2 here)

(2) Capital cities. A provincial capital city or a municipality directly under the central government can be considered a "policy city" in the sense that it receives all kinds of 
favorable economic policies and resource allocation from central and local governments, even more so during the planned economy period. If we treat location-specific policies as general locational fundamentals, then, these capital cities have advantages comparable to natural tourist attractions in tourism cities. There are 32 capital cities in China. Using Guangzhou as the reference city, panel 2 of Table 4 shows that Beijing, Shanghai, and Shenyang grow parallel with Guangzhou.

(3) Coastal cities. Coastal cities are harbor cities and enjoy natural location advantage in transportation. They are also the cities that started transition in the early stage of China economic reform and have received favorable government intervention. Choosing Shantou as the reference city, panel 3 shows that Sanya, Shenzhen, and Xiamen grow parallel with Shantou. We should point out that Shantou, Shenzhen, and Xiamen are three of the five cities in the special economic zones.

(4) Yangtze River Delta cities. Cities in this region have both transportation advantage (near the Yangtze River and the Pacific Ocean) and policy advantage (receiving favorable open and reform policies); furthermore, this region is one of the manufacturing industry clusters. Panel 4 shows that Hangzhou, Nantong, and Suzhou grow parallel with Shanghai.

(5) Pearl River Delta cities. Cities in this area enjoy advantages similar to Yangtze River Delta cities. They also attract labor-intensive manufacturing firms. Panel 5 shows that Guangzhou, Shenzhen, and Zhongshan grow parallel with Jiangmen.

(6) Southwestern cities. Southwestern cities are located in less developed Southwestern China, with less developed transportation network and a large minority population. Taking cities in Sichuan province as examples, panel 6 shows that Chengdu, Leshan, and Mianyang grow parallel with Panzhihua when a structural change is taken into account. 
(7) Northeastern cities. Northeastern region is a traditional heavy industry center and a mining center. Panel 7 of Table 4 shows that Anshan, Benxi, and Fuxin grow parallel with Liaoyang conditional on a structural change. Anshan, Benxi and Liaoyang are well-known for their steel industry; Fuxin, for its coal mining industry. This panel suggests that natural resource endowment might play an important role in long run growth of "resource cities.”

After examining the above seven groups of cities, we have found rare evidence for the simple, deterministic, parallel growth among Chinese cities. However, after taking into account growth trend and structural change in city sizes, we find some pairs of cities with common group characteristics do grow parallel in terms of generalized concept of parallel growth. Those common characteristics can be summarized as generalized locational fundamentals, including natural tourist attractions (tourist cities), transportation advantages (coastal cities), natural resource endowment such as coal mine (resource cities), and similar government interventions (policy cities). If we extend the definition of locational fundamentals to any location specific amenities, including natural resources, transport accessibility, and government interventions, the identified parallel growth patterns of sub-groups lend some support to the locational fundamentals theory.

Our findings are consistent with a few studies that confirm the important role that locational fundamentals play on urban growth. For example, Beeson, DeJong, and Troesken (2001) use the US census data from 1840 to 1990 and find that locational fundamentals (including both natural characteristics such as access to water transportation and produced characteristics such as educational infrastructures) can explain cross-county variations in population in 1990 as well as in 1840; furthermore, produced characteristics in 1840 has a significant, persistent effect on population growth over the 150 years. Ayuda, 
Collantes, and Pinilla (2005) find that many European countries show a similar spatial pattern that population concentration persists throughout industrialization and post-industrialization period in locations where population concentration in pre-industrialization period was already high. They also confirmed this pattern by constructing a data set for Spain from the period 1787-2000 and regressing provincial population density (or change of population density) on a set of natural advantage variables such as altitude, rainfall, and coastal location (or plus initial density). They find that not only do location fundamentals affect population concentration contemporaneously, but also initial population concentration reinforces later population growth, suggesting that not only are first nature advantages crucial to urban growth, but also first nature advantage may help generate forces of increasing returns to scale in later period. González-Val and Olmo (2010) also conclude that both locational fundamentals and increasing-returns-to-scale forces can explain the growth of income and city population in American cities.

Another point worth noting is that structural changes occur to the growth path of many cities. This is not surprising since transition to a market economy and rapid urbanization in China are accompanied by dramatic institutional changes and government interventions, such as the Western region development plan and favorable economic policies to the Pearl River Delta and Yangtze River Delta regions. Our research show that it is important to take into account structural changes when studying city size distribution and city size dynamics for developing countries.

Finally, our findings provide a possible linkage to reconcile random growth theory and locational fundamental theory. Davis and Weinstein (2002) conclude that the transitory 
effect of large shocks to city size is a rejection of random growth theory and a supportive evidence for locational fundamental theory. Our findings suggest that city size growth path can be random but the path may be determined by locational fundamentals.

\section{Conclusions}

Four types of urban growth theories are closely related to parallel growth: the endogenous growth theory predicts deterministic, parallel growth; the random growth theory and hybrid growth theory imply random, parallel growth in the long run; and the locational fundamentals theory suggests that cities with similar locational fundamentals grow parallel. However, little empirical evidence is available so far for parallel growth. This paper focuses on identifying the parallel growth patterns of Chinese cities based on these theories and time series properties of the data. Given the fact that China is still in the period of rapid urbanization, even though we apply rigorous time series econometric techniques, we can only tentatively conclude that the overall Chinese city growth does not follow parallel growth. However, once allowing for growth trend and structural change, we find that a small number of cities with certain common group characteristics, such as similar location advantages or policy regime, do grow parallel. For example, super large-sized capital cities Guangzhou and Shanghai grow parallel; Northeastern steel industry cities Anshan and Liaoyang grow parallel; Shenzhen and Xiamen, both in special economic zones, also grow parallel. Our findings suggest that location fundamentals may have persistent impacts on urban growth. Furthermore, if we extend the concept of locational fundamentals to any location-specific factors, including natural resource endowment, transport accessibility, and government interventions, our findings provide some evidence supporting the locational fundamentals urban growth theory. 
Although the generalized parallel growth patterns we have detected between some Chinese cities lend some support to locational fundamental theory, we did not directly test locational fundamental theory. This could be done by collecting locational fundamental characteristics for Chinese cities and following strategies in Beeson, DeJong, and Troesken (2001) and other similar studies. Our research focuses on only cities from the balanced panel (having observations since 1984). However, one of the striking features of Chinese urbanization is the entry of new cities each year. It would be interesting to investigate the growth evolution incorporating migration and the birth of new cities. In addition, we are interested in only identifying the growth patterns in this paper, but urban growth determinants are also interesting and warrant further studies.

\section{References}

Anderson, G., Ge, Y., 2005. The size distribution of Chinese cities. Regional Science and Urban Economics 36, 756-776.

Ayuda, M., Collantes, F., Pinilla, V., 2005. From locational fundamentals to increasing returns: The spatial concentration of population in Spain, 1787-2000. Working Paper, Universidad de Zaragoza.

Angel, S., Sheppard, S., Civco D., 2005. The dynamics of global urban expansion. Report, Transport and Urban Development Department, The World Bank.

Baxter, M., 1998. Interpolating annual data into monthly or quarterly data. Government Statistical Service Methodology Series No. 6. London: Office for National Statistics.

Beeson, P., DeJong, D., Troesken, W., 2001. Population growth in U.S. counties, 1840-1990. Regional Science and Urban Economics 31, 669-699. 
Bernanke, B., Gertler, M., Watson, M., 1997. Systematic monetary policy and the effects of oil price shocks. Brookings Papers on Economic Activity 1, 91-142.

Black, D., Henderson, V., 1997. Urban growth. NBER Working Paper No.6008.

Black, D., Henderson, V., 1999. A theory of urban growth. Journal of Political Economy $107,252-284$.

Bosker, M., Brakman, S., Garretsen, H., Schramm, M., 2008. A century of shocks: The evolution of the German city size distribution 1925-1999. Regional Science and Urban Economics 38, 330-347.

Brakman, S., Garretsen, H., Schramm, M., 2004. The strategic bombing of German cities during World War II and its impact on city growth. Journal of Economic Geography 4, 201-218.

Cordoba, J., 2007. On the distribution of city sizes. Journal of Urban Economics 63, 177-197.

Davis, D., Weinstein, D., 2002. Bones, bombs and break points: the geography of economic activity. American Economic Review 92, 1269-1289.

DeJong, D., Nankervis, J., Savin, N., Whiteman, C., 1992. The power problems of unit root tests in time series with autoregressive errors. Journal of Econometrics 53, 323-343.

Dickey, D., Fuller, W., 1979. Distribution of the estimators for autoregressive time series with a unit root. Journal of the American Statistical Association 74, 427-431.

Eaton, J., Eckstein, Z., 1997. Cities and growth: Theory and evidence from France and Japan. Regional Science and Urban Economics 27, 443-474. 
Eeckhout, J., 2004. Gilbrat's law for (all) cities. American Economic Review 94, 1429-1451.

Fujita, M., Mori, T., 1996. The role of ports in the making of major cities: Self-agglomeration and hub-effect. Journal of Development Economics 49, 93-120.

Gabaix, X., 1999. Zipf's law for cities: An explanation. Quarterly Journal of Economics 114, 739-767.

Gabaix, X., Ioannides, Y., 2004. The evolution of city size distribution, in: Henderson, V. (Ed.). Handbook of Regional and Urban Economics, Vol 4. Amsterdam: North-Holland, 2341-2378.

Gan, L., Li D., Song, S., 2006. Is the Zipf's law spurious in explaining city-size distributions? Economics Letters 92, 256-262.

González-Val, R., Olmo, J., 2010. A statistical test of city growth: Location, increasing returns and random growth. MPRA Working Paper No.27139.

Henderson, V., Wang, H.G., 2007. Urbanization and city growth: The role of institutions. Regional Science and Urban Economics 37, 283-313.

Im, K., Pesaran, M., Shin, Y., 2003. Testing for unit roots in heterogeneous panels. Journal of Econometrics 115, 53-74.

Johansen, S., Juselius, K., 1990. Maximum likelihood estimation and inference on cointegration - with applications to the demand for money. Oxford Bulletin of Economics and Statistics 52, 169-210.

Junius, K., 1999. Primacy and economic development: Bell shaped or parallel growth of 
cities? Journal of Economic Development 24, 1-22.

Krugman, P., 1993. First nature, second nature, and metropolitan location. Journal of Regional Science 33, 129-144.

Krugman, P., 1996. Confronting the mystery of urban hierarchy. Journal of the Japanese and International Economies 10, 399-418.

Kwiatkowski, D., Phillips, P., Schmidt, P., Shin, Y., 1992. Testing the null hypothesis of stationarity against the alternative of a unit root: How sure are we that economic time series have a unit root? Journal of Econometrics 54, 159-178.

Levin, A., Lin, C.F., Chu, C.J., 2002. Unit root tests in panel data: Asymptotic and finite sample properties. Journal of Econometrics 108, 1-24.

Nitsch, V., 2005. Zipf zipped. Journal of Urban Economics 57, 86-100.

Parr, J., 1985. A note on the size distribution of cities over time. Journal of Urban Economics 18, 199-212.

Polèse, M., Denis-Jacob, J., 2010. Changes at the top: A cross-country examination over the 20th century of the rise (and fall) in rank of the top cities in national urban hierarchies. Urban Studies 47, 1843-1860.

Rosen, K., Resnick, M., 1980. The size distribution of cities: An examination of the Pareto law and primacy. Journal of Urban Economics 8, 165-186.

Rossi-Hansberg, E., Wright, M., 2007. Urban structure and growth. Review of Economic Studies 74, 597-624.

Schwert, G.W., 1989. Tests for unit roots: a Monte Carlo investigation. Journal of Business and Economic Statistics 7, 147-160. 
Sharma, S., 2003. Persistence and stability in city growth. Journal of Urban Economics 53, 300-320.

Song, S., Zhang, K., 2002. Urbanization and city size distribution in China. Urban Studies 39, 2317-2327.

Soo, K., 2005. Zipf’s law for cities: A cross country investigation. Regional Science and Urban Economics 35, 239-263.

Zipf, G., 1949. Human Behavior and the Principle of Least Effort. Cambridge: Addison-Wesley Press.

Zivot, E., Andrews, D., 1992. Further evidence on the great crash, the oil-price shock, and the unit-root hypothesis. Journal of Business and Economic Statistics 10, 251-70. 


\section{Appendix:}

Table 1: Different urban growth theories and their implications for parallel growth

\begin{tabular}{|l|l|l|l|}
\hline $\begin{array}{l}\text { Urban growth } \\
\text { theory }\end{array}$ & Representative studies & $\begin{array}{l}\text { Implication for growth rate of } \\
\text { city size }\end{array}$ & $\begin{array}{l}\text { Implication for parallel } \\
\text { growth }\end{array}$ \\
\hline $\begin{array}{l}\text { Endogenous } \\
\text { growth theory }\end{array}$ & $\begin{array}{l}\text { Black and Henderson } \\
\text { (1999); Eaton and } \\
\text { Eckstein (1997) }\end{array}$ & $\begin{array}{l}\text { Constant across cities and } \\
\text { time in steady state }\end{array}$ & Deterministic, parallel growth \\
\hline $\begin{array}{l}\text { Random growth } \\
\text { theory }\end{array}$ & $\begin{array}{l}\text { Cordoba (2007); } \\
\text { Gabaix (1999) }\end{array}$ & $\begin{array}{l}\text { Same mean and variance for } \\
\text { all cities across time; } \\
\text { independent of city sizes }\end{array}$ & $\begin{array}{l}\text { Stable city size distribution } \\
\text { following Zipf's law implies } \\
\text { parallel growth in the long run }\end{array}$ \\
\hline $\begin{array}{l}\text { Hybrid growth } \\
\text { theory }\end{array}$ & $\begin{array}{l}\text { Rossi-Hansberg and } \\
\text { Wright (2007) }\end{array}$ & $\begin{array}{l}\text { Same expected rate across } \\
\text { cities in steady state }\end{array}$ & $\begin{array}{l}\text { Parallel growth in the long run } \\
\text { but random deviation in the } \\
\text { short run }\end{array}$ \\
\hline $\begin{array}{l}\text { Locational } \\
\text { fundamentals } \\
\text { theory }\end{array}$ & $\begin{array}{l}\text { Fujita and Mori } \\
\text { (1996); Krugman } \\
\text { (1996) }\end{array}$ & $\begin{array}{l}\text { Initial conditions affect future } \\
\text { growth rate }\end{array}$ & $\begin{array}{l}\text { Cities with similar locational } \\
\text { fundamentals tend to grow } \\
\text { parallel }\end{array}$ \\
\hline
\end{tabular}


Table 2

Time variations of the Zipf's exponent

\begin{tabular}{cccccccc}
\hline \multicolumn{2}{c}{ All cities } & \multicolumn{2}{c}{$\begin{array}{c}\text { Cities with } \\
\text { population }>200,000\end{array}$} & \multicolumn{2}{c}{$\begin{array}{c}\text { Cities with } \\
\text { population }>500,000\end{array}$} & $\begin{array}{c}\text { Balanced } \\
\text { panel }\end{array}$ \\
\hline Year & $\begin{array}{c}\text { Number } \\
\text { of cities }\end{array}$ & $\beta$ & $\begin{array}{c}\text { Number } \\
\text { of cities }\end{array}$ & $\beta$ & $\begin{array}{c}\text { Number } \\
\text { of cities }\end{array}$ & $\beta$ & $\beta$ \\
\hline 1984 & 295 & 0.891 & 131 & 1.266 & 50 & 1.463 & 0.879 \\
1985 & 324 & 0.856 & 146 & 1.275 & 52 & 1.459 & 0.895 \\
1986 & 342 & 0.857 & 149 & 1.260 & 54 & 1.447 & 0.904 \\
1987 & 382 & 0.884 & 158 & 1.260 & 55 & 1.445 & 0.904 \\
1988 & 434 & 0.927 & 168 & 1.273 & 58 & 1.440 & 0.919 \\
1989 & 450 & 0.932 & 175 & 1.282 & 58 & 1.429 & 0.925 \\
1990 & 468 & 0.902 & 177 & 1.253 & 60 & 1.381 & 0.929 \\
1991 & 479 & 0.923 & 182 & 1.289 & 61 & 1.423 & 0.934 \\
1992 & 514 & 0.950 & 201 & 1.302 & 62 & 1.433 & 0.941 \\
1993 & 569 & 0.981 & 228 & 1.343 & 69 & 1.433 & 0.942 \\
1994 & 622 & 1.007 & 248 & 1.377 & 73 & 1.453 & 0.961 \\
1995 & 640 & 1.023 & 267 & 1.383 & 76 & 1.451 & 0.965 \\
1996 & 665 & 1.038 & 273 & 1.388 & 78 & 1.454 & 0.968 \\
1997 & 666 & 1.032 & 285 & 1.389 & 81 & 1.452 & 0.978 \\
1998 & 665 & 1.047 & 291 & 1.383 & 86 & 1.457 & 0.988 \\
1999 & 665 & 1.075 & 302 & 1.380 & 86 & 1.423 & 0.990 \\
2000 & 661 & 1.025 & 293 & 1.364 & 92 & 1.412 & 0.989 \\
2001 & 662 & 1.026 & 304 & 1.357 & 105 & 1.430 & 0.993 \\
2002 & 656 & 1.001 & 311 & 1.339 & 108 & 1.448 & 0.972 \\
2003 & 653 & 0.986 & 324 & 1.269 & 122 & 1.416 & 0.897 \\
2004 & 655 & 1.024 & 348 & 1.290 & 130 & 1.412 & 0.945 \\
2005 & 659 & 1.117 & 581 & 1.473 & 363 & 1.939 & 1.073 \\
2006 & 659 & 1.129 & 586 & 1.480 & 368 & 1.936 & 1.072 \\
\hline
\end{tabular}

Note: The balanced panel includes 259 cities. All regressions have good fit; most of the $p$-values for testing the null hypothesis $H_{0}: \beta=1$ are zeroes. Two cities (Lasa and Hailaer) have missing population data in various years and are not included in analysis. 
Table 3

Testing stationarity of city sizes

\begin{tabular}{|c|c|c|c|c|}
\hline City name & ADF test & KPSS test & ZA test & Break point date \\
\hline \multicolumn{5}{|c|}{ Examples of cities with inconsistent testing results } \\
\hline Anyang & -1.950 & 0.142 & $-5.413^{*}$ & 2002Q4 \\
\hline Baoji & -3.093 & 0.063 & -3.934 & 1997Q4 \\
\hline Baotou & -2.595 & 0.078 & -3.722 & 1989Q2 \\
\hline Binzhou & -2.081 & 0.095 & -3.438 & 1999Q3 \\
\hline \multicolumn{5}{|c|}{ Examples of cities that are trend stationary } \\
\hline Dazhou & $-3.710^{*}$ & 0.142 & $-5.117^{*}$ & 1992Q4 \\
\hline Deyang & $-3.850^{*}$ & 0.089 & -4.245 & 1993Q3 \\
\hline Jingmen & $-3.812^{*}$ & 0.067 & $-4.993^{*}$ & 1992Q4 \\
\hline Xiangfan & $-4.240^{*}$ & 0.141 & $-7.361^{*}$ & 2003Q2 \\
\hline \multicolumn{5}{|c|}{ Examples of cities that are non-stationary } \\
\hline Shanghai & -0.134 & $0.268^{*}$ & -1.762 & 2003Q3 \\
\hline Beijing & -2.886 & $0.270^{*}$ & -3.305 & 1990Q1 \\
\hline Chongqin & -0.463 & $0.272^{*}$ & -1.394 & 1990Q2 \\
\hline Guangzhou & -2.008 & $0.235^{*}$ & $-8.171^{*}$ & 1999Q4 \\
\hline
\end{tabular}

Note: For the ADF test, the null hypothesis is non-stationarity; the critical value for the $5 \%$ level is -3.46; the superscript " "” indicates rejection of non-stationarity at least at the $5 \%$ level. For the KPSS test, the null hypothesis is trend stationarity; the critical value for the $5 \%$ level is 0.15 ; the superscript "*” indicates rejection of stationarity at least at the $5 \%$ level. For the ZA test, the null hypothesis is non-stationarity without a break point and the alternative hypothesis is trend stationarity with an endogenous break point; the critical value for the $5 \%$ level is -4.80 ; the superscript “"” indicates rejection of non-stationarity without a break point at least at the $5 \%$ level. 
Table 4

Testing for parallel growth of city sizes

\begin{tabular}{|c|c|c|c|c|}
\hline Cities & $\mathrm{ADF}$ & KPSS & ZA & Break point date \\
\hline \multicolumn{5}{|c|}{ Group 1: Tourism cities (Guilin as reference city) } \\
\hline Hangzhou & -1.165 & $0.270^{*}$ & $-7.029^{*}$ & 2000Q4 \\
\hline Suzhou & -0.976 & $0.253^{*}$ & $-6.945^{*}$ & $2000 \mathrm{Q} 4$ \\
\hline Xian & $-4.024^{*}$ & 0.138 & $-5.518^{*}$ & 1994Q4 \\
\hline \multicolumn{5}{|c|}{ Group 2: Capital cities (Guangzhou as reference city) } \\
\hline Beijing & -2.244 & $0.171^{*}$ & $-6.117^{*}$ & 2001Q2 \\
\hline Shanghai & -2.706 & $0.169^{*}$ & $-6.325^{*}$ & 1999Q4 \\
\hline Shenyang & -3.225 & $0.252^{*}$ & $-6.982^{*}$ & 1999Q3 \\
\hline \multicolumn{5}{|c|}{ Group 3: Coastal cities(Shantou as reference city) } \\
\hline Sanya & -0.779 & $0.230^{*}$ & $-8.196^{*}$ & 2002Q3 \\
\hline Shenzhen & -0.797 & $0.257^{*}$ & $-6.413^{*}$ & 2002Q3 \\
\hline Xiamen & -0.977 & $0.182^{*}$ & $-8.189^{*}$ & 2002Q4 \\
\hline \multicolumn{5}{|c|}{ Group 4: Yangtze River Delta cities (Shanghai as reference city) } \\
\hline Hangzhou & -0.0994 & $0.263^{*}$ & $-6.870^{*}$ & $2000 Q 3$ \\
\hline Nantong & -1.417 & $0.148^{*}$ & $-6.013^{*}$ & 2002Q3 \\
\hline Suzhou & -0.832 & $0.243^{*}$ & $-6.389^{*}$ & $2000 Q 4$ \\
\hline \multicolumn{5}{|c|}{ Group 5: Pearl River Delta cities (Jiangmen as reference city) } \\
\hline Guangzhou & -2.503 & $0.165^{*}$ & $-5.550^{*}$ & 2002Q3 \\
\hline Shenzhen & -1.113 & $0.248^{*}$ & $-5.138^{*}$ & 2002Q1 \\
\hline Zhongshan & -1.236 & $0.187^{*}$ & $-8.363^{*}$ & 2001Q4 \\
\hline \multicolumn{5}{|c|}{ Group 6: Southwestern cities (Panzhihua as reference city) } \\
\hline Chengdu & -0.768 & $0.253^{*}$ & $-6.451^{*}$ & 1989Q4 \\
\hline Leshan & -2.969 & 0.078 & $-5.488^{*}$ & 1998Q4 \\
\hline Mianyang & -2.293 & $0.190^{*}$ & $-5.539^{*}$ & 2002Q3 \\
\hline \multicolumn{5}{|c|}{ Group 7: Northeastern cities (Liaoyang as reference city) } \\
\hline Anshan & -0.647 & $0.169^{*}$ & $-4.917^{*}$ & 1989Q4 \\
\hline Benxi & -1.536 & $0.159^{*}$ & $-4.956^{*}$ & 1993Q3 \\
\hline Fuxin & -1.174 & 0.145 & $-5.226^{*}$ & 1993Q3 \\
\hline
\end{tabular}

Note: For the ADF test, the null hypothesis is non-stationarity; the critical value for the $5 \%$ level is -3.46; the superscript "*” indicates rejection of non-stationarity at least at the $5 \%$ level. For the KPSS test, the null hypothesis is trend stationarity; the critical value for the $5 \%$ level is 0.15 ; the superscript "“" indicates rejection of stationarity at least at the $5 \%$ level. For the ZA test, the null hypothesis is non-stationarity without a break point and the alternative hypothesis is trend stationarity with an endogenous break point; the critical value for the $5 \%$ level is -4.80 ; the superscript “*” indicates rejection of non-stationarity without a break point at least at the $5 \%$ level. 


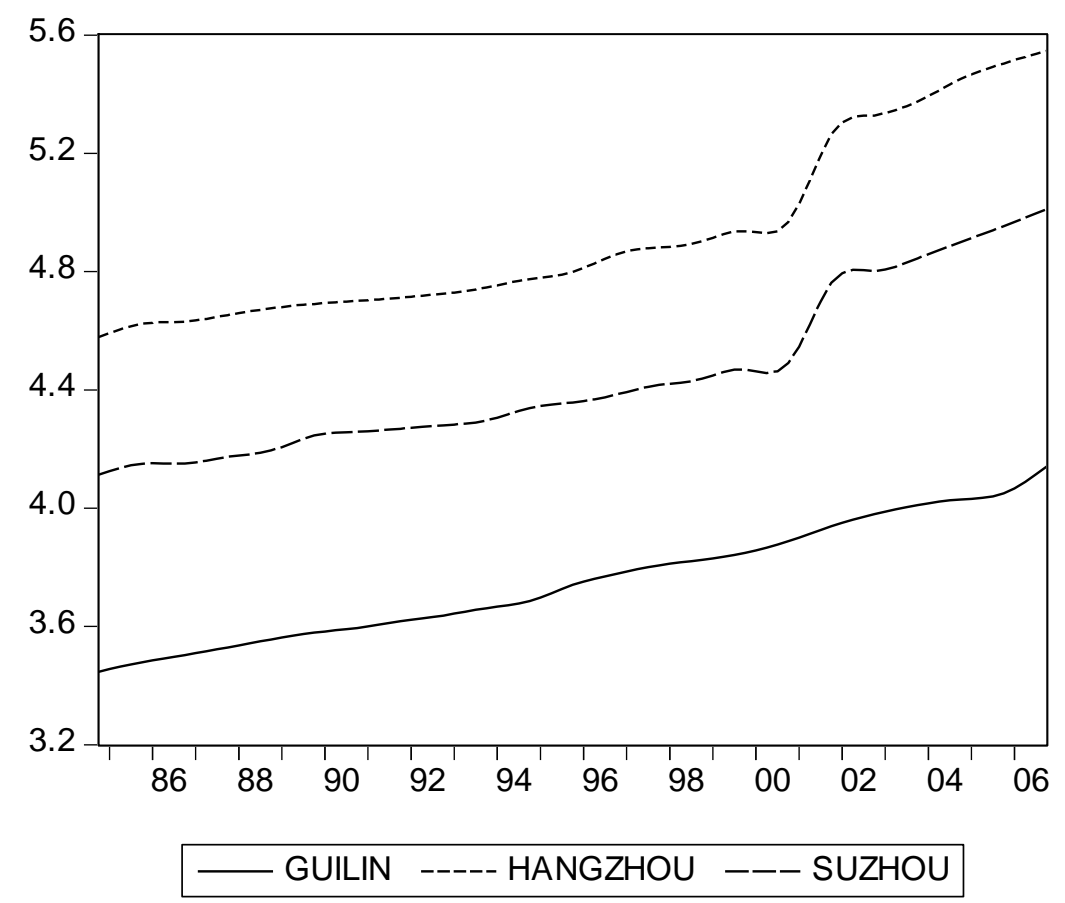

Figure 1 Population levels of three tourism cities

Note. The vertical axis is the logarithm of city population; the horizontal axis is year.

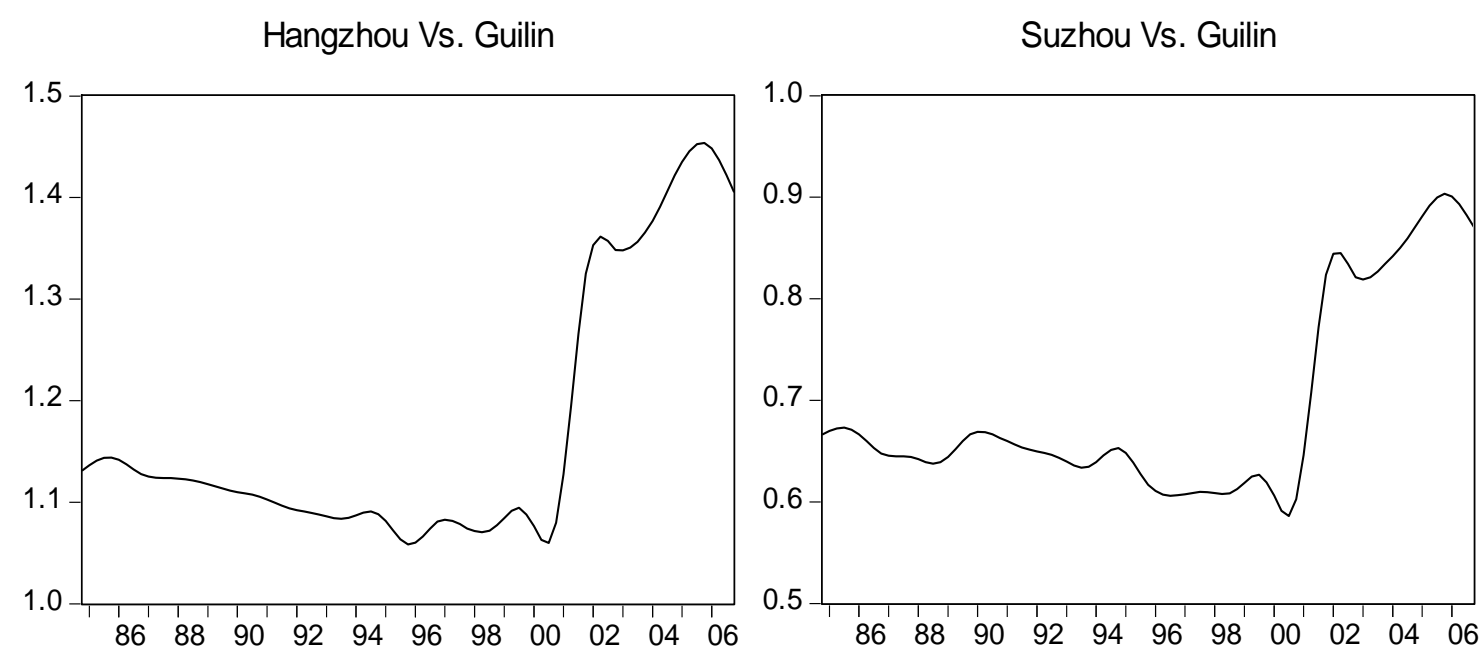

Figure 2 Logarithm of population ratio

Note. The vertical axis of the left panel is the logarithm of population ratio of Hangzhou to Guilin; the vertical axis of the right panel is the logarithm of population ratio of Suzhou to Guilin; the horizontal axis is year. 